Sports Training

\title{
Relationship between Sprint, lower limb power, and change of direction speed in adolescents
}

\author{
Júlio Brugnara Mello ${ }^{1}$ (D), Eraldo dos Santos Pinheiro ${ }^{2}$ (D), Gustavo Dias Ferreira ${ }^{2}$ (D), \\ Gabriel Gustavo Bergmann ${ }^{2}$ \\ ${ }^{I}$ Faculdade SOGIPA de Educação Física, Grupo de Pesquisa Projeto Esporte Brasil, Porto \\ Alegre, RS, Brasil; ${ }^{2}$ Universidade Federal de Pelotas, Laboratório de Estudos em Esportes \\ Coletivos, Pelotas, RS, Brasil.
}

Associate Editor: Romulo A Fernandes, UNESP, Presidente Prudente, SP, Brasil.

\begin{abstract}
Aim: The purpose of this study is to verify the association between sprint, lower limb power, and change of direction speed in schoolchildren. Method: This is a cross-sectional school-based study with a probabilistic sample $(n=1455)$ of adolescents aged 10-17 years. The variables were: sex, chronological age, body mass, height, skinfold sum, maturity offset, lower limb power, change of direction speed, and sprint. For the data analyses, we used a t-test for independent samples, Pearson correlation, and multiple linear regression. A statistical significance level of 5\% was considered for all analyses. Results: The three variables of physical fitness presented moderate and significant correlations between them $(\mathrm{r}=\{0.39-0.61\})$. Three models were tested with sprint (model 1), change of direction sprint (model 2) and lower limb power (model 3 ) as an outcome. Predictors tested explain $47 \%$ of model $1,49 \%$ of model 2 , and $54 \%$ of model 3. The individual predictor's contribution in both models varied between $0.1 \%$ to $38 \%$. Conclusions: The evidence suggests that change of direction speed and sprint, together with sex, body mass, and skinfold sum account for approximately $54 \%$ of the variance of lower limb power in adolescents aged $10-17$ years.
\end{abstract}

Keywords: Psychomotor Performance, physical fitness, adolescent.

\section{Introduction}

Long-term athletic development programs should provide children and adolescents with a variety of training forms to improve health and performance-related fitness ${ }^{1}$. In this perspective, some proposals indicate that holistic development of physical fitness throughout childhood and adolescence is the most suitable alternative ${ }^{2}$. Functional capacities such as strength, power, cardiorespiratory fitness, balance, coordination, speed, and agility are identified as fundamental to long-term development in children and adolescents ${ }^{1,3}$.

Among this range of functional capacities, variables such as power, change of direction speed, and sprint being among the main physical capacities to good performance on different intermittent sports ${ }^{4,5}$. Many training programs are conducted with plyometric exercises, high-intensity interval training, and specific strength and power exercise considering this relevance ${ }^{6,7}$. In addition, a good level of these physical capacities is import for engaging in school sports $^{8}$ and this engagement can be favorable to high performance in posterior phases.

To these variables to be trained effectively, it is necessary to understand several aspects related to trainability, among them the relationship of physical capacities to each other. Knowing this relationship is one of the ways to improve the training's optimization capacity ${ }^{9}$, regardless of age group, skill level, and sporting aspirations ${ }^{2}$.

The relationship between power, sprint, and change of direction speed in high-performance adult athletes is well established in scientific literature ${ }^{3,10,11}$. A series of studies suggest a hypothesis of a theoretical model of associations that approach an adequate optimization for training, showing that power training, primarily plyometric, has a positive effect on sprint and change of direction speed ${ }^{9,12}$. Although this hypothesis is consistent, all studies about that were conducted with different modalities young athletes. In this way, the association between these physical capacities is not clear about the adolescent population, including no-athlete adolescents, adolescents involved in sports/physical activities for health or schoolsport team.

To collaborate with the understanding of this association, we propose a study carried out with a representative sample of a school-based population. It should be emphasized that evidence in the population context is an important step towards understanding the relationship between adolescents' functional capacities. In addition, we consider the fact that most adolescents engaged in high-performance sports originally started their sports life 
at school $^{8}$, so, we must consider that in these places there are adolescents with different physical, morphological and behavioral characteristics. In this sense, this study aimed to verify the association between sprint, power of lower limbs and change of direction speed in adolescents.

\section{Methods}

This cross-sectional school-based study is part of the research project entitled "Habitual physical activity and associated factors in schoolchildren from Uruguaiana Brazil" conducted with adolescents aged 10-17, enrolled in the day shift of the public schools at Uruguaiana, Brazil. The project was approved by the research ethics committee of the Universidade Federal do Pampa, under protocol 042/2010.

\section{Population and sample}

The study population, according to Brazilian Basic Education School Census ${ }^{13}$, was 15,210 adolescents in our focus age group. The sample calculation to estimate prevalence was carried out based on the following criteria: a) population of 15,210 adolescents; b) prevalence of physical inactivity estimated at $70 \%$; c) $95 \%$ confidence interval $(95 \% \mathrm{CI})$; d) sampling error of 3 percentage points; e) delineation effect (deff) equal to 1.5; and f) an increase of $15 \%$ to cover possible losses and refusals. With the adoption of these criteria, the need to evaluate 1,398 students was estimated.

The sampling criterion adopted was probabilistic in multiple stages. The municipality was divided into five geographical areas, four in the urban area and one rural area. The number of schools and students enrolled in each area was identified. From this, nine schools were selected in the urban area, three in one of the urban areas and two in each of the remaining three areas. For rural adolescents, it was necessary to select, among all the schools in this area, only one school. All students, of the proposed age group, were invited to participate in the study and during this occasion, the objectives and procedures of the study were presented, and the terms of free and informed consent and consent were given.

The inclusion criteria were a) being enrolled in the public school system in the municipality; and b) present the free and informed consent form signed by parents or guardian and express a willingness to participate (by signing the consent form). Adolescents outside the age group of interest and those with any type of disability that placed them as outliers in the results of physical tests were excluded from the analyzes. In these cases, with proper authorization, adolescents participated in data collection but were not part of the present study. Therefore, after all processes, the study has data about 1,455 adolescents.

\section{Data collection procedure}

Data collection was performed from 2011 April to September. Detail about data collection procedure has been described previously ${ }^{14}$. The variables used in the present study were sex, chronological age, body mass, height, skinfolds sum ( $\sum \mathrm{SS}$ ), maturity offset, lower limb power, change of direction speed, and sprint. The research project data were collected in the schools' gymnasiums and sports courts by previously trained evaluators ( 3 professors and 12 graduate students of the institution where the study was conducted). The team of evaluators was composed of researchers and graduate students of Physical Education with previous training. Data collections occurred during the school shift and the order of collections was: 1) application of questionnaires (1 professor and 1 graduate student); 2) anthropometric assessments (1 professor and 1 graduate student); 3) physical tests (1 professor and 10 graduate students).

Anthropometric variables were measured as described prevously. ${ }^{15}$ The measurements occurred three times and the average value was considered for the analyses. The body mass measurement was performed with a digital scale (Plenna, Brazil) with a capacity of $150 \mathrm{~kg}$ and an accuracy of 100 grams. Skin folds were collected using a scientific plicometer (Cescorf, Brazil) with an accuracy of $1 \mathrm{~mm}$. The values of tricipital and subscapular SS were added, and the sum of skinfolds ( $\sum \mathrm{SS}$ ) was created. Anthropometric assessments were carried out by two members of the team on all research subjects. For maturity offset calculation were used the equation recommended for Moore et al. ${ }^{16}$. This equation uses height and decimal age to estimate the peak growth velocity, in this way, were used equation:

$$
\begin{aligned}
& \text { for boys }(-7.999994+(0.0036124 \times(\text { age } \times \text { height }))) \\
& \text { for girls }(-7.709133+(0.0042232 \times(\text { age } \times \text { height })))
\end{aligned}
$$

The physical tests are part of Projeto Esporte Brasil battery $^{17}$. The $20-\mathrm{m}$ run test and horizontal jump have international validation with good evidences ${ }^{18,19}$ and $4 \times 4 \mathrm{~m}$ run (square) test was used in 8000 children and adolescents Brazilian sample ${ }^{20}$.

The power of lower limbs was assessed by the horizontal jump test, performed with a measuring tape fixed to the ground, perpendicular to a starting line. The adolescents were placed immediately behind the line, with feet parallel, slightly apart, knees semi-flexed, trunk projected in front. At the signal, the adolescents should jump as far as possible, landing with both feet simultaneously. The adolescents performed the test twice and the evaluator noted the best performance in $\mathrm{cm}$ to one decimal place.

The change of direction speed was assessed using the square test. For the test, a four-meter square is marked on the side with a cone at each angle. The student started from the standing position. At the signal, the student 
should move at full speed and touch the cone located on the diagonal of the square. Then, you should run to touch the cone on your left (or right) and then the other diagonal. Finally, it should run towards the last cone. The appraiser was positioned slightly beside the start/finish cone. The adolescents performed the test twice and the evaluator noted the best time in seconds to two decimal places.

The sprint was assessed by the 20-meter run test. The track was marked with three parallel lines on the ground as follows: starting line, timing line $(20 \mathrm{~m})$, and finishing line ( $2 \mathrm{~m}$ after the second line). The third served to avoid the deceleration before the timing line. The appraiser was positioned slightly beside the timing line. The adolescents performed the test twice and the evaluator noted the best time in seconds to two decimal places.

\section{Statistical analysis}

Initially, the normality of the distributions was tested using the Kolmogorov-Smirnov test. As all variables show themselves to be parametric, the mean and standard deviation for both sexes were used to describe them. For comparisons between sex, the $t$-test for independent samples was used. Levene's test was used previously and for all variables the equality in variances was considered. To identify associations between physical fitness variables, Pearson's correlation test was chosen, considering $r$ between 0.3 and 0.6 as a moderate correlation and $r>0.6$ as a strong correlation ${ }^{21}$.

Subsequently, to identify the adjusted associations, we opted for multiple linear regression with the stepwise method, adjusting for sex (dummy variable), chronological age, body mass, and $\sum$ SS and maturity offset. These analyzes were performed first with the sprint as the outcome (model 1) of the regression model (tested theoretical model). Subsequently, the variables change of direction speed (model 2) and lower limb power (model 3) were tested as an outcome in separate models. This way of testing the different models is justified by the moderate correlation found between the variables in the entire sample. All analyzes were stratified by sex and with $95 \%$ confidence interval was taken into account. All data were analyzed using the IBM SPSS Statistics 20 .

\section{Result}

The first analysis shows that all variables have a normal distribution. Information related to each variable analysed across the group and stratified by sex is shown in Table 1. Only chronological age did not show a statistically significant difference between the sexes. The boys showed greater height and body mass, and better performances in the three tests of physical fitness. The girls had a higher $\sum S S$. Regarding somatic maturation, girls presented, on average, 1.4 years after the growth peak, whereas boys, on average, are 0.5 months before the growth peak.

The correlation analysis between the physical fitness variables indicated that, without stratifying the sample, there is a moderate correlation between sprint and lower limb power and change of direction speed and lower limb power. A high association was found between sprint and change of direction speed. So, the less time it takes to run the $20 \mathrm{~m}$ sprint, the greater the distance reached in the horizontal jump and the less time it takes to perform the square test. The coefficient of determination between sprint and change of direction speed, between lower limb power and sprint, and between lower limb power and change of direction speed suggests that the explanation of the variance of one variable by the variance of the other is approximately $38 \%, 30 \%$, and $34 \%$, respectively. When the analyses are performed by sex, the magnitude of the correlations remains moderate (Table 2).

Regarding the multiple linear regression analysis, the theoretical model tested (model 1) was significant and

Table 1 - Description of the analyzed variables and differences between the sex of adolescents aged 10-17.

\begin{tabular}{|c|c|c|c|c|c|c|c|c|c|}
\hline & \multicolumn{3}{|c|}{ All sample } & \multicolumn{3}{|c|}{ Boys } & \multicolumn{3}{|c|}{ Girls } \\
\hline & $\mathbf{n}$ & $\bar{x}$ & SD & $\mathbf{n}$ & $\bar{x}$ & SD & $\mathbf{N}$ & $\bar{x}$ & SD \\
\hline Chronological age (years) & 1455 & 13.56 & 2.02 & 714 & 13.55 & 2.02 & 741 & 13.57 & 2.02 \\
\hline Height $(\mathrm{cm})^{*}$ & 1372 & 157.82 & 10.60 & 684 & 159.73 & 12.45 & 688 & 155.92 & 7.95 \\
\hline Body mass $(\mathrm{kg})^{*}$ & 1374 & 52.77 & 13.82 & 685 & 53.61 & 15.18 & 689 & 51.94 & 12.27 \\
\hline$\sum \mathrm{SS}(\mathrm{mm}){ }^{* *}$ & 1273 & 40.28 & 17.75 & 674 & 35.06 & 17.12 & 599 & 46.16 & 16.57 \\
\hline Maturity offset (years) & 1372 & 0.7 & 1.8 & 684 & -0.05 & 1.7 & 688 & 1.4 & 1.6 \\
\hline $\operatorname{CDS}(\mathrm{s})$ & 1098 & 7.10 & 0.90 & 562 & 6.62 & 0.68 & 536 & 7.60 & 0.83 \\
\hline $\operatorname{LLP}(\mathrm{m})$ & 1111 & 141.52 & 32.61 & 565 & 159.36 & 31.55 & 546 & 123.06 & 21.56 \\
\hline Sprint (s) & 1097 & 4.06 & 0.61 & 562 & 3.78 & 0.49 & 535 & 4.36 & 0.59 \\
\hline
\end{tabular}

n: number; $\bar{x}$ : average; SD: standard deviation; $\sum$ SS: skinfolds sum; CDS: change of direction speed; LLP: lower limb power; cm: centimetres; kg: Kilograms; mm: millimetres; s: seconds; m: meters;

$\mathrm{p}<0,05$;

$\mathrm{p}<0,01$. 
Table 2 - Correlation between variables lower limb power, change of direction speed, and sprint from adolescents aged 10-17.

\begin{tabular}{|c|c|c|c|c|c|c|}
\hline \multicolumn{7}{|c|}{ All sample } \\
\hline & \multicolumn{3}{|c|}{ CDS } & \multicolumn{3}{|c|}{ LLP } \\
\hline & $\mathbf{r}$ & $\mathbf{R}^{2}$ & $\mathbf{p}$ & $\mathbf{r}$ & $\mathbf{R}^{2}$ & $\begin{array}{c}\text { p- } \\
\text { value }\end{array}$ \\
\hline Sprint & 0.616 & $\begin{array}{c}0.379 \\
(\mathrm{n}=1075)\end{array}$ & $<0.01$ & $\begin{array}{c}-0.556 \\
(\mathrm{n}=1083)\end{array}$ & 0.309 & $<0.01$ \\
\hline CDS & & & & $\begin{array}{c}-0.582 \\
(\mathrm{n}=1080)\end{array}$ & 0.339 & $<0.01$ \\
\hline
\end{tabular}

\begin{tabular}{lcccccc}
\hline \multicolumn{7}{c}{ Boys } \\
\hline & $\mathbf{r}$ & $\mathbf{R}^{2}$ & $\mathbf{p}$ & $\mathbf{r}$ & $\mathbf{R}^{2}$ & $\begin{array}{c}\text { p- } \\
\text { value }\end{array}$ \\
& & & & & & \\
Sprint & 0.495 & $0.245(\mathrm{n}=553)$ & $<0.01$ & $-0.415(\mathrm{n}=554)$ & 0.172 & $<0.01$ \\
CDS & & & & $-0.392(\mathrm{n}=554)$ & 0.154 & $<0.01$
\end{tabular}

\begin{tabular}{lccccccc}
\hline \multicolumn{7}{c}{ Girls } \\
\hline \multicolumn{1}{c}{$\mathbf{r}$} & $\mathbf{R}^{2}$ & $\mathbf{p}$ & $\mathbf{r}$ & $\mathbf{R}^{2}$ & $\begin{array}{c}\mathbf{p}- \\
\text { value }\end{array}$ \\
Sprint & 0.477 & $0.228(\mathrm{n}=522)$ & $<0.01$ & $-0.423(\mathrm{n}=529)$ & 0.179 & $<0.01$ \\
CDS & & & & $-0.448(\mathrm{n}=526)$ & 0.201 & $<0.01$ \\
\hline
\end{tabular}

CDS: change of direction speed; LLP: lower limb power; r: correlation value; $R^{2}$ : Determination coefficient.

presented a determination coefficient of 0.47 . In other words, we can infer that for the studied population, the variables sex, height, $\sum \mathrm{SS}$, lower limb power, and change of direction speed together explain $47 \%$ of the sprint variability (Table 3 ). The second model tested the change of direction speed as an outcome (Table 3). The associations remained significant and the adjustment variables remained in the model. The variability of lower limb power and sprint, together with the other variables, explain approximately $49 \%$ of the variability of the change of direction speed in the population studied.

The third regression model tested (Table 3) was the best statistical model found. All associations remained, as well as the adjustment variables. In addition, the variability in change of direction speed and sprint explained $54 \%$ of the variability of lower limb power in the population studied, along with the other adjustment variables. For all models, the $\mathrm{R}^{2}$ change indicates the individual percent of explaining for each model variable.

\section{Discussion}

This study presents insight into the associations between the change of direction speed, sprint, and lower limb power in an adolescent population. Our main results demonstrate that the model that had the highest predictive capacity had the change of direction speed and the sprint,
Table 3 - Multiple linear regression models to estimate the associations between sprint, lower limb power, change of direction speed and adjustment variables $(\mathrm{n}=1,066)$.

\begin{tabular}{|c|c|c|c|c|}
\hline \multicolumn{5}{|c|}{ Model 1: sprint } \\
\hline Model's Variables & B & CI 95\% & $\mathbf{R}^{2}$ change & $\begin{array}{c}\text { p- } \\
\text { value }\end{array}$ \\
\hline Constant & 3.648 & $3.102-4.194$ & & $<0.001$ \\
\hline CDS & 0.247 & $0.208-0.286$ & 0.380 & $<0.001$ \\
\hline LLP & -0.003 & $\begin{array}{c}-0.004- \\
-0.002\end{array}$ & 0.065 & $<0.001$ \\
\hline$\sum \mathrm{SS}$ & 0.007 & $0.005-0.010$ & 0.011 & $<0.001$ \\
\hline Height & -0.008 & $\begin{array}{c}-0.011- \\
-0.006\end{array}$ & 0.015 & $<0.001$ \\
\hline Sex & 0.156 & $0.088-0.224$ & 0.010 & $<0.001$ \\
\hline \multicolumn{5}{|l|}{ Model 1} \\
\hline $\mathrm{R}^{2}$ adjusted & & & 0.479 & \\
\hline \multicolumn{5}{|l|}{$\mathrm{SEE}=0.44$} \\
\hline \multicolumn{5}{|l|}{$\mathrm{F}=20.375 ; \mathrm{p}<0.001$} \\
\hline \multicolumn{5}{|c|}{ Model 2: Change of direction speed } \\
\hline Model's Variables & $\mathbf{B}$ & CI 95\% & $\mathbf{R}^{2}$ change & $\begin{array}{c}\text { p- } \\
\text { value }\end{array}$ \\
\hline Constant & 5.270 & $4.790-5.750$ & & $<0.001$ \\
\hline Sprint & 0.538 & $0.460-0.617$ & 0.380 & $<0.001$ \\
\hline LLP & -0.007 & $\begin{array}{c}-0.008- \\
-0.005\end{array}$ & 0.080 & $<0.001$ \\
\hline Sex & 0.402 & $0.307-0.497$ & 0.033 & $<0.001$ \\
\hline \multicolumn{5}{|l|}{ Model 2} \\
\hline $\mathrm{R}^{2}$ adjusted & & & 0.491 & \\
\hline \multicolumn{5}{|l|}{$\mathrm{SEE}=0.63$} \\
\hline \multicolumn{5}{|l|}{$\mathrm{F}=68.825 ; \mathrm{p}<0.001$} \\
\hline \multicolumn{5}{|c|}{ Model 3: Lower limb power } \\
\hline & B & CI 95\% & $\begin{array}{c}R^{2} R^{2} \\
\text { change }\end{array}$ & $\begin{array}{c}\text { p- } \\
\text { value }\end{array}$ \\
\hline Constant & 246.32 & $\begin{array}{c}231.80- \\
260.83\end{array}$ & & $<0.001$ \\
\hline CDS & -7.58 & $-9.64--5.52$ & 0.33 & $<0.001$ \\
\hline Sprint & -8.52 & $\begin{array}{c}-11.51- \\
-5.54\end{array}$ & 0.013 & $<0.001$ \\
\hline$\sum S S$ & -1.18 & $-1.35--1.01$ & 0.06 & $<0.001$ \\
\hline Body mass & 0.73 & $0.59-0.87$ & 0.02 & $<0.001$ \\
\hline Sex & -15.45 & $\begin{array}{c}-18.76- \\
-12.15\end{array}$ & 0.08 & $<0.001$ \\
\hline \multicolumn{5}{|l|}{ Model 3} \\
\hline $\mathrm{R}^{2}$ adjusted & & & 0.544 & \\
\hline \multicolumn{5}{|l|}{$\mathrm{SEE}=22.26$} \\
\hline $\begin{array}{l}\mathrm{F}=31.429 \\
\mathrm{p}=<0.001\end{array}$ & & & & \\
\hline
\end{tabular}

$\mathrm{R}^{2}$ : Determination coefficient; F: F statistic; $\mathrm{p}$ : model significance; SEE: standart error of the estimate; B: Beta coefficient; CI 95\%: Confidence interval of $95 \%$; $\sum$ SS: skinfolds sum; CDS: change of direction speed; LLP: lower limb power. 
together with sex, body mass, and $\sum$ SS explaining approximately $54 \%$ of the variance of lower limb power.

The correlation between lower limb power and change of direction speed found was moderate, as well as previous studies carried out with young athletes of the same age group as the participants in this study ${ }^{11,22,23}$. Regarding the correlation between lower limb power and sprint, the study by Marques et al. ${ }^{22}$ presented a lower correlation $(r=0.29)$ than that we found. However, in the study by Bojikianet al. ${ }^{23}$, the correlation was high, but when the analysis was controlled by age, the correlation becomes moderate. It is noteworthy that only the study by Alemdaroğlu ${ }^{11}$ did not use the horizontal jump and that all of the aforementioned studies presented different procedures for measuring and evaluating the change of direction speed and sprint.

This divergence between the results demonstrates the complexity in predicting the lower limb's power from the sprint and the change of direction speed (model 3 of regression). We must consider that the performance in these variables is determined by different factors associated with rapid energy transfer, a predominance of fasttwitch muscle fiber, increased motor neuron excitability and nerve conduction speed, development of concentric strength, time of contact with the ground, and condition training ${ }^{24-26}$.

One of the aspects common to the performance of lower limb's power, sprint, and change of direction speed is the use of elastic energy, produced by the stretching and shortening cycle to produce strength ${ }^{27}$. Although this cycle has a greater emphasis on lower limb power, this characteristic in common may partly explain the high $\mathrm{R}^{2}$ change of each physical capacity in both association models (e.g. model 2: sprint had $38 \%\left[\mathrm{R}^{2}\right.$ change $\left.=0.380\right]$ of explaining to change of direction speed variance).

Our results are consistent with the literature ${ }^{11,22,23,28}$, furthermore, mechanically, physical capabilities that involve muscle power have strength and speed as components ${ }^{29}$. Thus, it becomes coherent to realize that change of direction speed is a physical component with a strong association with lower limb power, due to the mechanical component involved in the action of the two tests (square test and horizontal jump).

The physical fitness performance analyzed here is primarily related to the biological structure of the adolescents $^{11,28}$. The improvement of these factors will occur according to the stimuli offered, which are related to lifestyles, participation in physical activities, physical exercises, eating and sleeping habits, but an important variable that can change the fitness levels is biological maturation.

Therefore, as physical fitness is multifactorial, it is important to highlight that the sample selection procedure constitutes a strong point of this study, as it is consistent to assume the existence of variability, both in lifestyles and in biological characteristics among study participants.
This attributes precision to the results found. Considering these characteristics, the determination coefficients presented in the three regression models $(47 \%, 49 \%$, and 54\%) are considered high.

Regarding the applicability of these findings in the scope of school sports, the results suggest that any of the variables can be worked or tested in order to develop or identify the performance of the others. Still, as normally in school and initiation sports, the volume and frequency with which training (classes) take place are reduced and the technical, tactical, and practical aspects of the sport itself occupy a high percentage of time during activities.

The teacher or coach can optimize physical training by working one physical capacity per training, especially considering the associations presented in the regression model 3. In high-performance sports, mainly youth, the theoretical model (model 1) must prevail for the optimization of training. In this case, it is convenient for the coach, after a high level of performance, to develop skills such as sprint and change of direction speed from power training, such as plyometric training ${ }^{3}$.

This study has some limitations and strengths that need to be highlighted. The limitations are 1) not to use important confounding variables in the association models, such as biological maturation and physical activity; 2) not to define in the sample the adolescents who are or are not sports practitioners or athletes; 3 ) the technical measurement error of the evaluator in the anthropometric variables was not registered by researchers; and 4) the $4 \times 4$ square test for change of direction speed measurement have no validation parameters published. These limitations need to be taken into account when interpreting the results. However, the strengths are 1) a study conducted with a representative sample, which ensures that the data can be extrapolated to the adolescent population; and 2) a study that addresses a theme that is widely disseminated with specific groups of athletes for the population of adolescents, mainly schoolchildren.

\section{Conclusion}

Our results demonstrate a moderate correlation between the physical capacities of students aged 10-17 in both sexes. The model that had the highest predictive capacity had the change of direction speed and the sprint, together with sex, body mass, $\sum \mathrm{SS}$, and chronological age, explaining approximately $55 \%$ of the variance of lower limb power. Despite the lower percentage of explanation, the regression models that considered sprint and change of direction speed as outcomes were also significant and can be considered in the sports initiation in the school context. 


\section{Acknowledgments}

Scholarship from Brazilian government by from Coordenação de Aperfeiçoamento de Pessoal de Nível Superior (CAPES).

\section{References}

1. Lloyd RS, Cronin JB, Faigenbaum AD, Haff GG, Howard R, Kraemer WJ, et al. National Strength and Conditioning Association Position Statement on Long-Term Athletic Development. J Strength Cond Res. 2016;30(6):1491-509. doi:10.1519/JSC.0000000000001387

2. Oliver JL, Lloyd RS, Meyers RW. Training Elite Child Athletes: Promoting Welfare and Well-Being. Strength Cond J. 2011;33(4):73-9. doi:10.1519/SSC.0b013e318216a9b6

3. Slimani M, Chamari K, Miarka B, Del Vecchio FB, Chéour F. Effects of Plyometric Training on Physical Fitness in Team Sport Athletes: A Systematic Review. J Hum Kinet. 2016;53(1):231-47. doi:10.1515/hukin-2016-0026

4. McCormick BT, Hannon JC, Newton M, Shultz B, Detling N, Young WB. The Effects of Frontal- and Sagittal-Plane Plyometrics on Change-of-Direction Speed and Power in Adolescent Female Basketball Players. Int J Sports Physiol Perform. 2016;11(1):102-7. doi:10.1123/ijspp.2015-0058

5. Durguerian A, Piscione J, Mathieu B, Lacome M. Integrating Strength and Power Development in the Long-Term Athletic Development of Young Rugby Union Players. Strength Cond J. 2019;41(4):18-33. doi:10.1519/SSC.0000000000000452

6. Foss KDB, Thomas S, Khoury JC, Myer GD, Hewett TE. A school-based neuromuscular training program and sportrelated injury incidence: A prospective randomized controlled clinical trial. J Athl Train. 2018. doi:10.4085/10626050-173-16

7. Wang Y-C, Zhang N. Effects of plyometric training on soccer players. Exp Ther Med. 2016;12(2):550-4. doi:10.3892/ etm.2016.3419

8. Lovell TWJ, Fransen J, Bocking CJ, Coutts AJ. Factors affecting sports involvement in a school-based youth cohort: Implications for long-term athletic development. J Sports Sci. 2019;37(22):2522-9. doi:10.1080/ 02640414.2019.1647032

9. Pichardo AW, Oliver JL, Harrison CB, Maulder PS, Lloyd RS. Integrating models of long-term athletic development to maximize the physical development of youth. Int J Sports Sci Coach. 2018;13(6):1189-99. doi:10.1177/ 1747954118785503

10. Dello Iacono A, Martone D, Milic M, Padulo J. Vertical- vs. Horizontal-Oriented Drop Jump Training. J Strength Cond Res. 2017;31(4):921-31. doi:10.1519/JSC.0000000000001555

11. Alemdaroğlu $U$. The Relationship Between Muscle Strength, Anaerobic Performance, Agility, Sprint Ability and Vertical Jump Performance in Professional Basketball Players. J Hum Kinet. 2012;31(1):149-58. doi:10.2478/ v10078-012-0016-6

12. Harries SK, Lubans DR, Buxton A, MacDougall THJ, Callister R. Effects of 12-Week Resistance Training on Sprint and Jump Performances in Competitive Adolescent Rugby
Union Players. J Strength Cond Res. 2018;32(10):2762-9. doi:10.1519/JSC.0000000000002119

13. INEP. Censo Escolar Da Educação Básica 2010: Resumo Técnico. Brasilia; 2011. http://download.inep.gov.br/educa cao_basica/censo_escolar/resumos_tecnicos/resumo_tecni co_censo_educacao_basica_2011.pdf

14. Mello JB, Hernandez MS, Farias VM, Pinheiro ES, Bergmann GG. Aptidão Física Relacionada ao Desempenho Motor de Adolescentes de Uruguaiana, Rio Grande do Sul. Rev Bras Ciência Mov. 2015;23(4):72-9. doi:10.18511/ 0103-1716/rbcm.v23n4p72-79

15. Gordon C, Chumlea W, Roche A. Stature, recumbent lenght, and weight. In: Anthropometric Standardization Reference Manual. 1988.

16. Moore SA, Mckay HA, Macdonald H, Nettlefold L, BaxterJones AD, Cameron N, et al. Enhancing a Somatic Maturity Prediction Model. Med Sci Sport Exerc. 2015;47(8):175564. doi:10.1249/MSS.0000000000000588

17. Gaya A, Gaya AR. Manual de Testes e Avaliação Do PROESP-Br. Porto Alegre: Editora Perfil. UFRGS; 2016.

18. Bös K, Schlenker L. Deutscher Motorik-Test 6-18 (DMT 6-18). In: Bildung Im Sport. Wiesbaden: VS Verlag für Sozialwissenschaften; 2011:337-55. doi:10.1007/978-3531-94026-7_21

19. Calleja-González JJ, Los Arcos A, Gaizka M, Casamichana D, San Román-Quintana J, Yanci J. Reproducibilidad de test de aceleración y cambio de dirección en fútbol. [Reproducibility of test acceleration and change of direction in football]. RICYDE Rev Int ciencias del Deport. 2015;11 (40):104-15. doi:10.5232/ricyde2015.04001

20. Mello JB, Nagorny GAK, Haiachi MDC, Gaya AR, Gaya ACA. Projeto Esporte Brasil: perfil da aptidão física relacionada ao desempenho esportivo de crianças e adolescentes. Brazilian J Kinanthropometry Hum Perform. 2016;18(6):658. doi:10.5007/1980-0037.2016v18n6p658

21. Malina RM. Tracking of Physical Activity and Physical Fitness across the Lifespan. Res Q Exerc Sport. 1996;67 (sup3):S48-57. doi:10.1080/02701367.1996.10608853

22. Marques MC, Travassos B, Almeida R. A força explosiva, velocidade e capacidades motoras específicas em futebolistas juniores amadores: Um estudo correlacional. Motricidade. 2010;6(3). doi:10.6063/motricidade.6(3).140

23. Bojikian LP, Teixeira CP, Böhme MTS, Ré AHN. Relações entre Crescimento, Desempenho Motor, Maturação Biológica e Idade Cronológica em Jovens do Sexo Masculino. Rev Bras Educ Física e Esporte. 2005;19(2):153-62. doi:10.1590/S1807-55092005000200006

24. Ross A, Leveritt M, Riek S. Neural Influences on Sprint Running. Sport Med. 2001;31(6):409-25. doi:10.2165/ 00007256-200131060-00002

25. Lockie RG, Murphy AJ, Knight TJ, Janse de Jonge XA. Factors That Differentiate Acceleration Ability in Field Sport Athletes. J Strength Cond Res. 2011;25(10):2704-14. doi:10.1519/JSC.0b013e31820d9f17

26. Sleivert G, Taingahue $M$. The relationship between maximal jump-squat power and sprint acceleration in athletes. Eur J Appl Physiol. 2004;91(1):46-52. doi:10.1007/s00421003-0941-0 
27. Wilson JM, Flanagan EP. The Role of Elastic Energy in Activities with High Force and Power Requirements: A Brief Review. J Strength Cond Res. 2008;22(5):1705-15. doi:10.1519/JSC.0b013e31817ae4a7

28. Paul DJ, Gabbett TJ, Nassis GP. Agility in Team Sports: Testing, Training and Factors Affecting Performance. Sport Med. 2016;46(3):421-42. doi:10.1007/s40279-015-0428-2

29. Kawamori N, Haff GG. The Optimal Training Load for the Development of Muscular Power. J Strength Cond Res. 2004;18(3):675. doi:10.1519/1533-4287(2004)182.0.CO;2

\section{Corresponding author}

Name: Júlio Brugnara Mello, Professional Adress: Av. Benjamin Constant, 80, CEP 90550-003, Porto Alegre,
RS, Brasil.

E-mail: juliobmello@hotmail.com.

Manuscript received on September 16, 2020

Manuscript accepted on February 10, 2021

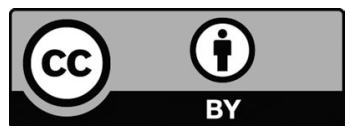

Motriz. The Journal of Physical Education. UNESP. Rio Claro, SP, Brazil - eISSN: 1980-6574 - under a license Creative Commons - Version 4.0 